\title{
Frege's Changing Conception of Number
}

\author{
by
}

\author{
KEVIN C. KLEMENT
}

University of Massachusetts

\begin{abstract}
I trace changes to Frege's understanding of numbers, arguing in particular that the view of arithmetic based in geometry developed at the end of his life (1924-1925) was not as radical a deviation from his views during the logicist period as some have suggested. Indeed, by looking at his earlier views regarding the connection between numbers and second-level concepts, his understanding of extensions of concepts, and the changes to his views, firstly, in between Grundlagen and Grundgesetze, and, later, after learning of Russell's paradox, this position is natural position for him to have retreated to, when properly understood.
\end{abstract}

Keywords: Frege, logicism, number, extensions, functions, concepts, objects

\section{Introduction}

IN THE FINAL YEAR of his life, having accepted that his initial attempts to understand the nature of numbers, in his own words, "seem to have ended in complete failure" (Frege, 1924c, p. 264; cf. 1924a, p. 263), Frege began what he called "A new attempt at a Foundation for Arithmetic" (Frege, 1924b). The most startling new aspect of this work is that Frege had come to the conclusion that our knowledge of arithmetic has a geometrical source:

The more I have thought the matter over, the more convinced I have become that arithmetic and geometry have developed on the same basis - a geometrical one in fact - so that mathematics is its entirety is really geometry. Only on this view does mathematics present itself as completely homogenous. (Frege, 1924c, p. 277)

This stands out in stark contrast with his earlier views, whereupon arithmetic, at least, was taken to be purely analytic. This meant that the "ultimate justification" for our acceptance of an arithmetical proposition, the proof of such a proposition, involves only general logical laws and definitions (Frege, 1950, sections 3, 12). In the longest extant manuscript from Frege's final year, "Sources of Knowledge of Mathematics and the Mathematical Natural Sciences," he distinguishes three possible sources of knowledge: (1) sense perception, (2) logic, and (3) geometrical and temporal sources. Logic is involved in all reasoning, so all domains of knowledge rely to some extent on (2); However, Frege now suggests that our knowledge even of arithmetic relies on both (2) and (3). Frege is explicit that the knowledge 
afforded by geometrical and temporal sources is still a priori; presumably what he had in mind then is something like Kantian pure intuitions of space and time.

We have in these finals works then what appears to be a radical shift away from Frege's former logicism. Indeed, Hans Sluga takes Frege in these manuscripts to have "broken the last tie to the logicist program", and to have come to the conclusion that "the foundations of arithmetic are not to be sought in logic at all, but in geometry" (Sluga, 1980, p. 173; emphasis added).

These late manuscripts are all very short, and lacking in detail. From them alone, we cannot get a full picture either of the exact motivations for Frege's new approach to arithmetic, or of the details of his "new attempt" at a foundation. We are left to speculate. However, I suggest that it is possible that the shift was not as radical a break as some have thought. Indeed, the changes to Frege's views can instead be understood as a natural outgrowth of a trajectory in his thought instigated by his learning of the contradictions plaguing his original logicism. I further argue that Frege's final views preserve the core of his previous conception of the nature of number and the meaningfulness of arithmetical discourse, and that indeed, that it is plausible to suppose that his appeal to geometry was designed precisely to patch up certain problems with his previous views that came to light because of the contradictions.

In order to support this position, however, we shall have to take another look at Frege's earlier works to get a sense of how precisely he understood his early claim that "a statement of number contains an assertion about a concept" - a doctrine he explicitly claimed to maintain even in this final period. Indeed, I shall spend much of what follows interpreting this claim as it appears in his 1884 Grundlagen der Arithmetik and in his 1893 Grundgesetze der Arithmetik. This discussion serves as the basis for my explanation for why it is he seems motivated to change his views in the precise way he does once he realized that his former robust realism about classes or the extensions of concepts could not be maintained.

Finally, I shall consider briefly another route to maintaining the core of his position Frege might have taken up instead, and speculate about why he might have shied away from it. Both the position Frege adopted, and the alternative position he might have adopted instead, have a number of attractions; indeed, they may still be views about the nature of numbers and our knowledge of arithmetic worth taking seriously as candidates for the truth (more or less). However, I shall briefly discuss some difficulties such approaches face.

\section{Grundlagen's discussion of Numbers as Second-Level Concepts}

Frege's classic 1884 Die Grundlagen der Arithmetik has a claim to being the most important work ever written in the philosophy of mathematics; the arguments 
against rival views on the nature of number early in the work are quite simply devastating. One of the major themes of the negative parts of the work is the extent to which the most prevalent views existing at that time as to the nature of number left out the close connection between numbers and concepts. The view that a number is a property belonging to everyday physical objects, or conglomerations or aggregates of such objects, failed to take into account the necessity of making reference to a concept in order to count; the same object could be described as fifty two playing cards, one deck and God-only-knows-how-many molecules (Frege, 1950, sections 22-23). Indeed, it would be plausible to describe the whole of books I-III of Grundlagen as leading up to what Frege there calls the "solution to the difficulty" (section 45), the realization that "a statement of number contains an assertion about a concept" (p. xi, cf. section 55). In making such claims as "Here are 500 men," "Venus has 0 moons," and "the King's carriage is drawn by four horses," I am predicating something of the concepts men that are present, moon of Venus and horse that draws the King's carriage.

Frege begins part IV by considering the view that a number simply is something that can be predicated of a concept: that a number simply is a "second-order" (or, in his later terminology, a "second-level") concept. On this view, the zero would be understood as a concept applicable to concept $F$ if and only if nothing falls under $F$, or, equivalently, everything does not fall under $F$. The other natural numbers could each be defined in terms of the previous number: $n+1$ would then be the concept applicable to $F$ just in case there is an object $a$ such that $a$ is $F$ and the number $n$ is applicable to the concept an $F$ that is not identical to $a$. In other words, the number $n$ would be a concept that could truly be predicated of $F$ just in case there were exactly $n F$ s. Given how naturally this conception of the nature of numbers is suggested by Frege's own conclusion that a statement of number is an assertion about a concept, and especially when contrasted with the relatively lengthy treatment given to much less initially attractive attempts to specify the nature of numbers, such as Euclid's and Schröder's, Frege's discussion of this conception of the nature of numbers is startlingly brief. His discussion lasts a mere two sections (sections 55-56) before he moves on to his more official portrayal of numbers as objects.

Of course this is not to say that Frege moves past the conception of numbers as second-level concepts without argumentation; indeed, as we shall see presently he gives three reasons to be wary of thinking of numbers in this way. However, I think the real reason Frege does not argue against this picture of numbers at length is that he does not ultimately see his own conception of the nature of numbers as a substantial deviation from this view. Instead, he sees it as an elaboration or stylistic improvement on this view with which it shares a common core.

The considerations Frege gives against taking numbers as second-level concepts in Grundlagen are the following: 
(1) It really only defines the expression "the number $n$ belongs to ..." and not the substantive phrase "the number $n$ " on its own;

(2) It cannot tell us whether or not any concept has the number Julius Cæsar belonging to it; and finally

(3) It gives us no means for establishing the identity of numbers, and hence does not fully license use of the definite article in the phase "the number of $F \mathrm{~s}$ ".

It is clear that the first of these objections stems from certain convictions on Frege's part regarding the functioning of language. What Frege calls "complete" expressions, proper names and definite descriptions in the singular, refer to objects. Concepts, which Frege identifies with a species of functions, are instead referred to by predicative or incomplete expressions. Thus as Frege explains, while the entire phrase "the number $n$ belongs to" requires completion by an expression for a concept, so it can be understood as referring to a concept or property of concepts. But he points out that the phrase "the number $n$ " is only part of the phrase "the number $n$ belongs to"; and it is this part, and only this part, that represents the number itself. In arithmetic, we refer to numbers by means of numerals such as "3" and "412", which do not appear in any way predicative. Hence Frege concludes that we need a conception of what a number is according to which it appears as "a self-subsistent object that can be recognized as the same again" (1950, section 56).

In the subsequent discussion, in the attempt to solve problems (2) and (3) Frege settles on the view that the number belonging to a concept $F$ is to be defined as the extension of the concept equinumerous with $F$, where equinumerosity is a relation between concepts that can be defined purely logically in terms of one-toone correspondence. This view avoids problem (1) in that Frege takes extensions of concepts to be objects, potentially to be referred to by complete expressions. Provided we have clear identity conditions for extensions of concepts - which Frege took for granted that we do - it solves problem (3). Lastly, it solves problem (2), or would solve it, if we had a means of determining whether or not Julius Cæsar is the extension of a concept (though in the end Frege himself does not fully address whether or not we do).

So how far does this view deviate from the simpler view according to which a number simply is defined as a second-level concept? The first thing to notice is that the number zero, on the new view, is precisely the extension of the concept with which zero would have been identified if numbers had been portrayed as second-level concepts. Frege now defines zero as the extension of the concept equinumerous with the concept not-identical-to-self. The concepts that would fall in this extension would be those concepts under which no objects fall. Although it takes a bit more effort to see, the same would hold for the other natural numbers as Frege defines them. 


\section{Numbers, Concepts and Extensions from Grundlagen to Grundgesetze}

The foregoing is enough to establish at least a very close connection between the conception of numbers as second-level concepts and Frege's official conception of numbers. The connection becomes closer still given Frege's rather unusual view about the relationship between concepts and their extensions. Indeed, on my own interpretation, for Frege, the extension of a concept is nothing but the concept itself considered as an object, rather than as something incomplete or predicative. While Frege is not quite as explicit about this as he could have been, the view comes out a number of places in Frege's writings, both early and late. In Grundlagen, it comes out only in a number of footnotes. Towards the end of the book, when summarizing his reasons for treating numbers as objects, Frege wrote:

... we concluded that a statement of number asserts something objective of a concept. We attempted next to define the individual numbers 0,1 , etc., and the step from one number to the next in the number series. Our first attempt broke down, because we had defined only the predicate which we said was asserted of the concept, but had not given separate definitions of 0 or $1 \ldots$ This resulted in our being unable to prove the identity of numbers. It became clear that the number studied by arithmetic must be conceived not as a dependent attribute, but substantivally. (1950, section 106)

He adds a footnote here reading, "the distinction corresponds to that between 'blue' and 'the colour of the sky'." If we attempt to understand the distinction Frege makes between "blue" and "the colour of the sky" as one dealing with the metaphysical nature of what corresponds to these objects in the world, we may be at a loss. Both would seem to represent a certain quality that some physical objects have and others do not. The distinction is rather between the adjective "blue", which represents a concept, something occurring predicatively, and the substantive noun phrase, "the colour of the sky", which according to Frege's views on language, would have to refer to an object.

As Frege was aware, number expressions can occur grammatically both as substantives as well as in adjectival contexts, such as in "Four horses pulled the wagon." While it is true that he points out that the adjectival uses can be reworded or rephrased to make use of a substantive form: in this case, for example, we might say instead, "Four is the number of horses that pulled the wagon," this does not really constitute an argument that what number words represent are really objects, and only objects. If it did, then a similar argument could be used to establish that what the adjective "blue" represents is an object, since we could always reword adjectival uses of "blue" with another phrasing involving the substantive phrase "the color blue". He argument seems rather to be that in arithmetic, number words almost always occur substantivally, and that since in arithmetic we are concerned with such issues as the identity or equality of numbers, for the purposes of arithmetic, we conceive of numbers as objects. The same might be true if we are 
concerned with the color of the sky, and recognizing it "as the same again" as the color of a certain book, or someone's eyes. In such cases we reconceive of the color as a "self-subsistent thing", as an object.

This does not yet explain how it is that when we move from considering the content of a number word occurring predicatively to the content of a number word as a substantive, what we end up thinking about is the extension of a concept. However, in an earlier footnote, appended to his definition of "the number which belongs to the concept $F$ " as "the extension of the concept equinumerous with the concept $F$ ", Frege wrote:

I believe that for "extension of the concept" we could write simply "concept". But I believe this would be open to the two objections:

1. that this contradicts my earlier statement that the individual numbers are objects, as is indicated by the use of the definite article in expressions like "the number two" ... and by the fact that the number constitutes an element in the predicate of a statement of number.

2. that concepts can have identical extensions without themselves coinciding.

I am, as it happens, convinced that both these objections can be met; but to do so would take us too far afield for present purposes. (Frege, 1950, p. 80)

Here Frege suggests that it would be just as correct to define "the number of $F \mathrm{~s}$ " as "the concept equinumerous with $F$ " as it would to define it as "the extension of the concept equinumerous with $F$ ". He then notes two objections to this suggestion, and professes that he thinks these objections can be met. Since Frege does not fully elaborate we are left to speculate precisely how it is he would meet them.

Frege does not discuss the nature of concepts and their extensions in any detail in his works prior to the 1890s. I think the resources are there in the views of the 1890s for explaining how the alternative wording of the definition might sidestep the two worries outlined. I should be explicit however that it is not clear the extent to which these views were already in place in 1884; so I temporarily bracket the question as to whether this is precisely what Frege had in mind in the earlier footnote to Grundlagen, although I think it most likely that he had in mind something at least broadly similar to what I am about to write.

In his 1892 essay, "On Concept and Object," Frege, notoriously, argued that phrases of the form "the concept $F$ ", as they themselves are not predicative, refer to objects and not to concepts:

In logical discussions one quite often needs to say something about a concept, and to express this in the form usual of such predications - viz., to make what is said about the concept into the content of the grammatical predicate. Consequently, one would expect that the reference of the grammatical subject would be the concept; but the concept as such cannot play this part, in view of its predicative nature; it must first be converted into an object, or, more precisely, an object must go proxy for it. We designate this concept by prefixing the words 'the concept', e.g.,

'The concept man is not empty.' 
Here the first three words are to be regarded as a proper name, which can no more be used predicatively than 'Berlin' or 'Vesuvius'. (Frege, 1892b, p. 185)

This suggests that for every concept, there is an object which the concept "converts into", or which goes proxy for the concept, when we attempt to think of the concept itself as the subject of what we are claiming. The connection between a concept and its "object-proxy" would naturally be quite close. This seems to be all the more the case given that it seems to be Frege's view that the thought expressed by the sentence, "the concept man is not empty" succeeds in being about the concept, even though it is not strictly speaking the concept that is referred to by the first three words. The thought would seem to be the same as the thought expressed by the sentence, "something is a man," in which the words ". . is a man" do occur predicatively. Indeed, Frege gives another example later in the paper more or less to this effect:

In the sentence, 'There is at least one square root of 4', we are saying something ... about a concept, square root of 4; viz., that it is not empty. But if I express the same thought thus: 'The concept square root of 4 is realized' then the first six words form the proper name of an object, and it is about this object that something is being said. (Frege, 1892b, pp. 187-88)

This statement, and others Frege makes suggest that Frege holds that every sentence involving a concept word occurring predicatively can be reworded in a form in which one finds instead a proper name referring to the proxy-object for that concept. Even something as simple as "Socrates is human" can be rephrased as "Socrates falls under the concept human", and here the last three words refer to an object (ibid., p. 193). The reworded sentence will be at least logically equivalent to the original. ${ }^{1}$

Hence, from this vantage point, if the phrase "the number of $F \mathrm{~s}$ " were defined as meaning the same as the substantive phrase "the concept equinumerous with the concept $F$ ", the reference of this phrase would not, strictly speaking, be a concept, but rather a proxy-object for a concept. In this case, the number zero would stand to the second-level concept applicable to a concept if no object falls under it the same way that the reference of "the concept horse" stands to the actual concept of being a horse. On this view, numbers would still be objects, and hence Frege would have no trouble deflecting the first worry to his rewording of the definition. Yet,

\footnotetext{
${ }^{1}$ Indeed, in the passage quoted from pp. $187-88$ of $1892 \mathrm{~b}$, Frege seems to suggest something stronger: that they express the very same thought. However, it is not entirely clear that this is consistent with Frege's other commitments regarding the nature of thoughts, and in particular, his claim that the sense expressed by a complete sentence is composed of the senses of the parts. Notice, e.g., that the sense of "Socrates falls under the concept human" would seem to be composed of more parts than that of the simpler "Socrates is human".
} 
at the same time, the connection between numbers and second-level concepts, and how it is that a statement of number could be regarded as making an assertion about a concept, would nevertheless be clear.

What then of the second worry for this way of rewording the definition? According to our current way of understanding the definition, "the number of popes" would be defined as the proxy-object for the concept equinumerous with the concept pope, and "the number of even primes" would be defined as the proxy-object of the concept equinumerous with the concept even prime. Now it can be established that every concept that is equinumerous with the concept pope is also equinumerous with the concept even prime, and vice versa. However, if distinct concepts can be coextensional, it does not follow from this that the concept of being equinumerous with the concept pope is the same as the concept of being equinumerous with the concept even prime. Assuming distinct concepts have distinct proxy-objects, it then similarly could not be concluded that the number of popes is the same as the number of even primes.

I believe this worry could be met by examining further Frege's notion of a concept. According to Frege's mature views, concepts are a species of function; in particular, they are functions whose value for every possible argument is a truthvalue, either the True, or the False (Frege 1891, p. 139; 1964, section 3). While it is meaningless to ask of two functions whether or not they stand to each other in first-level relation of identity, Frege suggests that there is an analogous secondlevel relation of coinciding that "holds between the concept $\Phi$ and the concept $X$, if every object that falls under $\Phi$ also falls under $X$, and conversely" (Frege, 1892a, p. 176). The concept having a heart maps exactly the same arguments to the True as does the concept having a kidney; so on this understanding of concepts, they would be the same concept. More generally, it seems Frege would regard functions as the same when they have the same value for every argument. To be sure, the phrase "has a heart" and the phrase "has a kidney" have distinct senses, but the concept itself, the reference of these expressions, is the same. Presumably, he also would say that second-level concepts coincide if they are applicable to precisely the same first-level concepts. Because the concept equinumerous with the concept pope is coextensional with the concept equinumerous with the concept even prime, for Frege, they are the same concept. It further stands to reason that coextensional concepts have identical proxy objects. Indeed Frege says as much:

Now we have seen that the relation of equality between objects cannot be conceived as holding between concepts too ... the only recourse we really have is to say 'the concept $\Phi$ is the same as the concept $X$ " and in saying this we have of course named a relation between objects [footnote: these objects have the name 'the concept $\Phi$ ' and 'the concept $\left.X^{\prime}\right] \ldots$ (Frege, 1892a, p. 177)

Hence it seems safe to conclude that the phrases "the concept equinumerous with the concept pope" and "the concept equinumerous with the concept even prime" 
refer to the same object. To be sure, we here have two distinct senses for this object, but this accords with the intuition that the phrases "the number of popes" and "the number of even primes" are coreferential expressions with distinct senses.

As we have seen, for Frege, concepts have the same identity conditions as their extensions. Indeed, no two concepts can have the same extension. Frege could, and I think did, go further. I believe Frege regarded the extension of a concept as the same thing as the proxy-object for a concept. Here it must be remembered that Frege did not regard the extension of a concept as a collection, aggregate or conglomeration of things, and indeed argued against such a view (Frege 1906, pp. 182-83; 1980, p. 142). Instead, he portrayed extensions of concepts as a special instance of what he called the Werthverlauf or "value-range" of a function (Frege 1891, pp. 139; 1964, section 3). It is clear from his discussion that by a "value-range" Frege had in mind the complete argument-value mapping for a function. Indeed, the word is one of several German mathematicians used at the time for the graph of a function, though of course Frege had in mind an abstract object and not some physical representation of ink or chalk. It is not uncommon for mathematicians to think of a function as nothing more than a mapping between arguments and values, and indeed, the set-theoretic conception of a function as a collection of ordered pairs is a testament to this. Given that Frege thinks that functions coincide when they have the same value for every argument, it would not be surprising for him to think that the object we refer to with a phrase of the form "the function F", i.e., the proxy-object for a function, would simply consist in such a mapping or graph considered in the abstract. If think of an extension of a concept as just such a value-range, then, it becomes natural to think of this as the proxy-object for a concept considered as a function. Frege's ill-fated Basic Law $\mathrm{V}$ is precisely the claim that functions have the same value-range whenever they have the same value for every argument.

Indeed, interpreting Frege's extensions as proxy-objects for concepts explains quite a few things within his writings.

First, it straightaway explains why it is that in his definition of number, he thinks one can replace the phrase "the extension of the concept" with the simpler "the concept". This suggestion is found not only in the footnote in Grundlagen, but in later writings as well (e.g. 1892b, p. 187). In a draft of "On Concept and Object," Frege wrote in a footnote that "whether one should simply put 'the concept' or 'the extension of the concept' is in my view one of expediency" (1892c, p. 106).

Second, it sheds light on why it is Frege makes such claims as that the "extension of a concept simply has its being in the concept, not in the objects which belong to it; these are not its parts" (1906, p. 183), and "the extension of a concept is constituted in being, not by the individuals, but by the concept itself" (1895, pp. 224-25). It is not entirely clear what it means metaphysically for one entity to "have its being" in another, but it is clear from the view we have described why 
it is that Frege would not have thought a concept and its extension to be metaphysically independent. The extension, on this view, simply is the concept conceived of as a logical subject, or deprived of its predicative or unsaturated nature. On a standard intensional view of concepts, of course, since multiple concepts can have the same extension, an extension would instead have to be thought of as independent of the concept.

Lastly, and in some ways most importantly, it helps explain why it is that the formal definition of numbers Frege gives in Grundgesetze has the appearance of deviating from that given in Grundlagen despite the fact that Frege himself writes as if they were equivalent. In Grundlagen, equinumerosity is defined as a relation between concepts, and the number of $F s$ defined as the extension of the concept equinumerous with $F$. The members of such an extension would then seem to be concepts: a number would be a class of concepts. In Grundgesetze, however, Frege first sketches how it is that by means of his notation for value-ranges every secondlevel function can be represented by a first-level function; in particular, Frege suggests that for every second-level function $M$ it is possible to define a first-level function $F$ such that the value of $M$ for a given function $\varphi$ is always the same as the value of $F$ for the value-range of $\varphi$ as argument (Frege, 1964, section 35). ${ }^{2}$ Frege then proceeds not to define a second-level relation of equinumerosity, but instead a first-level relation that holds between two objects when they are the extensions of equinumerous concepts (ibid., section 40). He then defines a function, whose value, for a given object as argument, is the class of all objects that bear this relation to the argument. Numbers are then portrayed as values of this function; " 0 " for example, is defined as the value of this function for the null class as argument (sections 40-41). It seems then that Frege has now redefined numbers as classes of like-membered classes, which leaves it mysterious at first why it is he claims in the same section of Grundgesetze that the definitions accord with those given in Grundlagen.

This mystery is easily explained away once the close connection between concepts and their extensions is put back into place. The argument Frege gives that every second-level concept can be represented by a first-level concept applicable to extensions is in keeping with - and most likely the source of - the suggestions in "On Concept and Object" that statements about concepts can be reworded or recaptured in terms of statements about their proxy objects. Bearing in mind that, for Frege, a class is simply an extension of a concept, his definition of numbers as classes of like-membered classes does not differ substantially from the definition

\footnotetext{
${ }^{2}$ This is in effect a more general version of what Cocchiarella (1987, p. 78) calls Frege's "Double Correlation Thesis", the suggestion that for every second-level concept there is a first-level concept which holds of a given object if and only if that object is the value-range of a concept to which the second-level concept applies.
} 
given in Grundlagen in which numbers are portrayed as extensions of concepts applicable to concepts. Indeed, if in Grundlagen definition of "the number of $F \mathrm{~s}$ " as "the extension of the concept equinumerous with the concept $F$ ", one takes not only the whole definiens as standing for a proxy-object, but also the sub-phrase "the concept $F$ " within it, which after all, appears in substantival form, one could even make a case that the technical definition given in Grundgesetze is what is actually intended by the definition given in Grundlagen.

I think then in the end that the conception of numbers found in Frege's classic works, even in the form of the Grundgesetze, is fully in keeping with his initial suggestion that a statement of number contains an assertion about a concept; indeed, in a sense a number can still be thought of as a sort of second-level concept, now recast however, as the proxy-object corresponding to a concept applicable to certain proxy-objects of concepts.

\section{Frege's Reaction to Russell's Paradox}

To his credit, Frege recognized immediately that Russell's paradox seriously threatened his conception of arithmetic and his conception of the extensions of concepts more generally. ${ }^{3}$ In the hastily prepared appendix added to volume II of Grundgesetze, Frege suggested a replacement for Basic Law V. It is now well known that the revised system is also inconsistent due to more complicated paradoxes (see, e.g., Quine, 1955). It is not known whether or not Frege ever knew that the revised system was formally flawed, but it is clear from his writings that he did not stay satisfied - if indeed he ever was satisfied - with the proposal from the appendix from a philosophical point of view. Nowhere in his extant writings from the period after 1902 do we find Frege endorsing the views of the appendix; instead we find many disparaging remarks to the effect that phrases of the form "the extension of $F$ " are logically objectionable, and even claims to the effect that

\footnotetext{
${ }^{3}$ It is often alleged that Frege reacted to the predicates or functions version of Russell's paradox by dismissing it as not applicable to him given his theory of levels of functions, which disallowed a function taking itself as argument, but that Frege was instead impressed by the class version of the paradox, both of which are described in Russell's letter. However, in fact, if I am right about Frege's attitude that extensions of concepts being what certain functions become when thought of as logical subjects, it becomes difficult to differentiate the two versions of the paradox, since the closest one could come in Frege's views to a function taking itself as argument would be a function taking its proxy-object as argument, or a concept being predicated of its own extension. Indeed, Frege did not dismiss the predicates version of Russell's paradox, but merely pointed out that Russell's wording of it was not as precise as could be: "Incidentally, the expression 'A predicate is predicated of itself' does not seem exact to me. A predicate is as a rule a first-level function which requires an object as argument and which cannot therefore have itself as argument (subject). Therefore, I would rather say: 'A concept is predicated of its own extension'.” (Frege, 1980, pp. 132-33)
} 
"the paradoxes of set theory ... have dealt the death blow to set theory itself" (Frege, 1924e, p. 269) and that "set theory [is] in ruins" (Frege, 1906, p. 176).

Given his initial conception of the nature of extensions of concepts and valueranges generally, it is not hard to see why he could not stay satisfied with the proposal given in the appendix. According to the replacement for Basic Law V, it is possible for two functions that diverge in value for certain arguments - in particular, those that diverge in value for their own value-ranges as argument - to nevertheless have the same value-range (Frege, 1964, p. 139). This of course is not only inconsistent with thinking of value-ranges as complete argument-value pairings for a given function, it is also inconsistent with thinking of a value-range as simply the object-proxy for the function, i.e., the function itself thought of as an object. ${ }^{4}$ Such an understanding of value-ranges really only makes sense if functions have the same identity conditions as their value-ranges. It would seem odd in the extreme to think that functions $F$ and $G$ could differ in value for certain arguments, and yet that when I use the phrases "the function $F$ " and "the function $G$ ", I am in fact referring to the very same thing.

What is particularly devastating about the failure of Frege's intuitive but naïve original conception of the relationship between concepts and their value-ranges is that it called into question whether it was ever possible to recognize the existence of objects using our logical faculties of reasoning alone. On his original view, the epistemological situation was fairly clear. Our logical capacities make use of certain concepts; by thinking of those concepts as logical subjects, or equivalently, by thinking of their extensions, our logical capacities are able to recognize and become aware of the existence of certain objects. It was by this means that Frege suggested we are able to become acquainted with and recognize the existence of numbers. His faith in the existence of extensions shattered, the problem of how it is we can recognize the existence of objects logically rose to the surface. He wrote the following to Russell in late 1902:

I myself was long reluctant to recognize value-ranges and hence classes; but I saw no other possibility of placing arithmetic on a logical foundation. But the question is, how do we apprehend logical objects? And I have found no other answer to it than this: we apprehend them as extensions of concepts, or more generally, as value-ranges of functions. I have always been aware that there are difficulties connected with this, and your discovery of the contradiction has added to them, but what other way is there? (Frege, 1980, pp. 140-41)

\footnotetext{
${ }^{4}$ Indeed, one may wonder how Frege would ever have come to consider such a view if my interpretation of the earlier period were right. Perhaps it was something like this: there is such a thing as the concept as a mapping of all pre-existing objects to the True or the False. It corresponds to a single value-range or proxy-object, the extension. But now that this object is added to the domain of objects, there are two concepts corresponding to what previously had been one concept: one in which the new object falls under it, and one where it does not. This might explain how two concepts can have as their proxy-object what had been one concept prior to the addition of this object.
} 
The worry is echoed in the Appendix, where Frege claims that the question "In what way are we to conceive logical objects, in particular, numbers?" as the prime problem of arithmetic, and admits that "this problem is not solved to degree I thought it was" (Frege, 1964, p. 143).

Frege's eventual conclusion seems to have been that logic alone cannot furnish us with knowledge of the existence of objects in this way, and that, despite appearances, there quite simply are no such objects as those referred to by phrases such as "the concept $F$ " or "the extension of the concept $F$ ". I think it is not often recognized the extent to which Frege's later writings on this issue are a drastic departure from the official view taken in "On Concept and Object." What is in common between his post-1903 writings on the subject and his earlier ones is that Frege rejects any argument to the effect that concepts must be objects simply because we seem to refer to a concept with a subject phrase of the form "the concept $F^{\prime}$. But in his earlier period, Frege did hold that such phrases had reference; they refer to objects. Indeed, he suggests that it is possible to reword statements about concepts into statements making use of such proper names. In his later writings, Frege suggests instead that such phrases mislead us into thinking that we have referred to an object, whereas in fact, we have not:

It is indeed strictly a mistake to say 'The concept positive number is satisfied', for by saying this I seem to make the concept into an object, as the definite article 'the concept' shows. It now looks as if 'the concept positive number' were a proper name designating an object and as if the intention were to assert of this object that it is satisfied. But the truth is that we do not have an object here at all. (Frege, 1914, pp. 249-50)

Notice that is precisely the opposite of the view expressed in "On Concept and Object," that the first six words of "The concept square root of 4 is realized" do refer to an object about which something is said (Frege, 1892b, p. 188; Cf. p. 184). Frege now claims that such phrases are "inappropriate" (1914, p. 239), a "logical defect in language" (1924e, p. 270). He reaches the same conclusion about phrases of the form "the extension of the concept star", writing that "this expression appears to designate an object; but there is no object for which this phrase could be a linguistically appropriate designation" (Frege, 1924e, p. 269).

Presumably he would not now claim that the sentence "The concept positive number is satisfied" is simply nonsense. Instead, the surface grammatical form of the statement is taken to be misleading. The grammatical subject seems to refer to an object; yet it does not. In this case at least, we can recapture the correct logical form by rewording so that the concept expressions appears again in a predicative position, i.e., "there are positive numbers" or " $\exists x(x$ is a positive number)". However, Frege claims, "Confusion is bound to arise if a concept word, as a result of transformation into a proper name, comes to be in a place in which it is unsuited" (Frege, 1980, p. 55). At the end of his life, Frege diagnosed the paradoxes as 
stemming from thinking one had gotten a hold of an object not only by using such phrases as "the concept $F$ " but also by means of such phrases as "the class of $F s$ ", "the system of $F$ " or the "the extension of $F$ ". He summarized the point in 1925 thusly: "We must set up a warning sign visible from afar: let no one imagine that he can transform a concept into an object" (Frege, 1980, p. 55). Now, much more than before, Frege warns of the logical imperfections of language, and the extent to which mathematicians, logicians and philosophers must be on guard against "the difficulties which this idiosyncrasy of language entangles us in" (Frege, 1924e, p. 270).

\section{Numbers as Concepts Revisited}

With the loss of his previous naïve views allowing a transformation from concepts to objects, Frege was left without a natural method of thinking of numbers as objects. One might, however, think that not all would be lost. With the loss of his previous naivety about such phrases as "the concept $F$ " or "the extension of $F$ ", one would think that Frege would no longer be swayed by his previous arguments to the effect that the numbers considered in arithmetic must be objects. After all, if grammar is not an infallible guide to logical form, if indeed, natural language, as Frege himself put it, was "not constructed from a logical blueprint" (Frege, 1924e, p. 269), there is little reason to think that the language of arithmetic would wear its logical form on its sleeve either. The fact that the numeral "2" appears as a proper name, or that we form expressions using the definite article such as "the number seven" should not be taken as decisive evidence that there must be objects corresponding to such phrases. Now, insofar as numerals and the like appear in sentences that have proper truth-conditions, Frege's own arguments against the formalists mitigate against the conclusion that such words are simply devoid of content altogether. However, room would seem open to Frege to simply identify numbers with second-level concepts; since this picture seems at least to get the right truthconditions for the way in which number words are used to make statements about concepts: nothing in the paradoxes of set theory had called that into question.

It will be recalled that in Grundlagen, Frege had three misgivings about the conception of numbers as second-level concepts. The first worry is in effect grammatical; with his newfound skepticism about the reliability of grammar, this worry could be dispatched. Similarly, Frege could simply dismiss the second worry: that involving whether or not Julius Cæsar is a number, as resulting from a misunderstanding. When it is properly understood in what context talk about numbers is meaningful, it will be found that it the question rests on a mistake. The last worry that involving how to identify a number as the same again - is perhaps the most serious. However, as we have seen, Frege did contend that a higher-level relation 
analogous to identity exists between concepts, and even gives a criterion for when this relation holds. Consequently, if we again return to the view that the number of $F \mathrm{~s}$ is the second-level concept applicable to a concept if and only if it is equinumerous with $F$ - and not the object-proxy or extension of this concept (for indeed, there is no such thing), we can hold that it is the same as the number of $F \mathrm{~s}$ if and only if it applies to the same first-level concepts. Since equinumerosity is an equivalence relation, we will get a version of Hume's Law: that the number of $F$ s coincides with the number of $G$ s if and only if $F$ is equinumerous with $G$, as desired.

There are, however, other roadblocks in the way of taking this approach. Most importantly, this version of Hume's Law does not allow us to deduce the existence or independence of any object. Given that numbers are no longer considered objects, this may not seem much of a problem. But it quickly becomes a problem when one attempts to deduce the basic desired attributes of numbers. Clearly, to make good on this approach, Frege's second-order function calculus would need to be expanded to (at least) become a third-order function calculus, so that we have variables and quantifiers for second-level functions. Otherwise, on this view, we would not be able to quantify over numbers. Once this change is made, and assuming suitable definitions are given of the second-level concept zero, the third-level relation of successorship, and the third-level concept of being a natural number, versions of four out of the five Peano postulates are readily forthcoming. ${ }^{5}$ The tricky one is the fourth Peano postulate, which states that no two natural numbers share the same successor. Unless it can be proven that there are infinitely many objects, this would be false. Suppose the number of objects is some finite number $n$. On our present view about what numbers are, the number $n$ is a second-level concept; in particular, it is a function that maps a first-level concept to the True just in case exactly $n$ objects fall under that first-level concept. There is such a first-level concept, viz., self-identity. Notice, however, that if concepts are individuated extensionally, this is the only first-level concept which the number $n$ applies. Any concept that does not map all objects to the True must map less than $n$ objects to the true, since $n$ is finite. The number $n+1$ would be a second-level concept applicable to a concept $F$ if and only if there is some $a$ falling under $F$ such that the concept an $F$ not identical to $a$ falls under $n$. Notice, however, that there could be no such $F$. Hence $n+1$ would be a second-level function mapping every firstlevel function to the False. Unfortunately, $n+2$ would be also be the second-level function mapping every first-level function to the False. However, since $n$ is distinct from $n+1$, but $n+1$ and $n+2$ would coincide, it would not always be the case that distinct natural numbers would have distinct successors.

${ }^{5}$ For details, see Landini (2006). 
If there are infinitely many objects, this problem is avoided, and Peano arithmetic at least can be recovered. Indeed, it is more or less for these reasons that in his own type-theoretic reconstruction of arithmetic, Russell had to assume infinitely many objects (see Russell, 1919, pp. 131-36). On his own views, Frege was able to guarantee that the series of natural numbers never reached an end, since it was always the case that there were at least $n+1$ objects for any natural number $n$, since the series of natural numbers up to and including $n$ has $n+1$ members. However, if numbers are not objects, this line of reasoning cannot be employed. Here, then we see the true cost of abandoning the view that concepts can be transformed into objects; without a way of recognizing the existence of objects logically, it seems that arithmetic cannot be given a purely logical foundation.

Unfortunately, there are very few surviving manuscripts from the period between Frege's becoming aware of the paradoxes and his "new attempt at a foundation" from 1924-25 in which Frege gives us any clue of the how his views about the nature of numbers had been changing or evolving in light of the failure of his former views. The best statement comes in the 1919 "Notes for Ludwig Darmstädter," where Frege seems clearly on the fence. He is still moved by his former reasons for taking numbers to be objects, if they are anything at all, yet seems swayed in thinking that the second-level concepts may be the best we can hope for:

Since a statement of number based on counting contains an assertion about a concept, in a logically perfect language a sentence used to make such a statement must contain two parts, first a sign for the concept about which the statement is made, and secondly a sign for a second-level concept. These second-level concepts form a series and there is a rule in accordance with which, if one of these concepts is given, we can specify the next. But still we do not have in them the numbers of arithmetic; we do not have objects, but concepts. How can we get from these concepts to the numbers of arithmetic in a way that cannot be faulted? Or are there simply no numbers in arithmetic? Could the numerals help to form signs for these second-level concepts, and yet not be signs in their own right? (Frege, 1919, p. 257)

This passage at least gives us insight into the trajectory of Frege's thought in light of the problems with his earlier views. He is still holding out for a view on which numbers might be recognized as objects, but is at least amenable to the view that perhaps the signs used in arithmetic are misleading in form, that numerals do not act as proper names, but instead in a more complicated fashion to get at secondlevel concepts.

\section{The Role for Geometry}

With this understanding of the direction of Frege's thought, I think we are finally in a position to understand what led him to the conclusion that geometrical sources of knowledge were necessary in arithmetic. 
In certain entries in his diary from 1924, Frege resigns himself to having failed in his "efforts to become clear about what is meant by number" (Frege, 1924a, p. 263). However, in particular, he accuses himself of having been misled by language into thinking that numbers are objects:

The sentences 'Six is an even number', 'Four is a square number', 'Five is a prime number' appear analogous to the sentences 'Sirius is a fixed star', 'Europe is a continent' - sentences whose function is to represent an object as falling under a concept. Thus the words 'six', 'four' and 'five' look like proper names of objects ...

But ... when one has been occupied with these questions for a long time one comes to suspect that our way of using language is misleading, that number-words are not proper names of objects at all ... and that consequently a sentence like 'Four is a square number' simply does not express that an object is subsumed under a concept and so just cannot be construed like the sentence 'Sirius is a fixed star'. But how then is it to be construed? (Frege, 1924a, p. 263)

Frege does not answer this question in this context; indeed, nowhere in this final period does he give a worked out view about how to understand such sentences. However, it seems fairly clear that the natural thing for him to have said is that the proper construal of statements about numbers is in terms of second-level concepts, and when we claim that a certain number has a certain feature, we are in effect claiming that a certain third-level concept applies to a second-level concept.

That it is this understanding of numbers Frege wishes to preserve in these writings is further attested by the precise role and importance he seems to assign to the geometrical source of knowledge: it is through it that we are able to come to recognize the existence of the infinite:

From the geometrical source of knowledge flows the infinite in the genuine and strictest sense of this word ... We have infinitely many points on every interval of a straight line, on every circle, and infinitely many lines through any point. (Frege, 1924e, p. 273)

Since, according to Frege, points in space are, logically considered, objects, the geometrical source of knowledge affords us knowledge of the existence of infinitely many objects. Frege is explicit that this sort of knowledge has both spatial and geometrical aspects, and that it is a priori and independent of sense perception:

It is evident that sense perception can yield nothing infinite. However many starts we may include in our inventories, there will never be infinitely many, and the same goes for us with the grains of sand on the seashore. And so, where we may legitimately claim to recognize the infinite, we have not obtained it from sense perception. For this we need a special source of knowledge, and one such is the geometrical.

Besides the spatial, the temporal must also be recognized. A source of knowledge corresponds to this too, and from this also we derive the infinite. Time stretching to infinity in both directions is like a line stretching to infinity in both directions. (Frege, 1924e, p. 274) 
A guarantee of infinitely many objects is precisely what is needed in order to guarantee that the sequence of natural numbers, when construed as second-level concepts, does not come to an end. That this is Frege's reason for appealing to the geometrical source of knowledge comes out rather explicitly in discussing the failure of his former views:

I myself at one time held it to be possible to conquer the entire number domain, continuing along a purely logical path from the kindergarten-numbers; I have seen the mistake in this. I was right in thinking that you cannot do this if you take an empirical route. I may have arrived at this conviction as a result of the following consideration: that the series of whole numbers should eventually come to an end, that there should be a greatest whole number, is manifestly absurd. This shows that arithmetic cannot be based on sense perception; for if it could be so based, we should have to reconcile ourselves to the brute fact of the series of whole numbers coming to an end, as we may one day have to reconcile ourselves to there being no stars above a certain size. But here surely the position is different: that the series of whole numbers should eventually come to an end is not just false: we find the idea absurd. So an a priori mode of cognition must be involved here. But this cognition does not have to flow from purely logical principles, as I originally assumed. There is the further possibility that it has a geometrical source (Frege, 1924d, pp. 276-277; Cf. 1924b, p. 279).

The upshot of the appeal to geometry seems precisely to afford us knowledge of the existence of objects, which Frege is now explicit that he thinks cannot be yielded by the logical source of knowledge alone (Frege, 1924b, p. 279). Once the existence of a sufficient number of objects is guaranteed in an a priori way, we are free to continue to understand a statement of number as containing an assertion about a concept: indeed, Frege is explicit in these final manuscripts that this is a thesis of his earlier work he still regards as true (Frege, 1924d, pp. 275-76; 1924b, p. 278).

If this is the right way to understand Frege's work in the period of 1924-25, it was not, I think, stemming from a complete change of heart of exactly what the essence of number consists in. Indeed, Frege's basic understanding of numbers in terms of concepts applicable to concepts remains more or less intact. Similarly, this work was not a full scale rejection of the importance of the logical source of knowledge for arithmetic. It was simply an admission that the purely logical concepts of arithmetic cannot guarantee the existence of objects, and because of this, we must rely on other a priori sources of knowledge to explain our conviction that the series of numbers does not end. It is perhaps correct to say that this position cannot correctly be described as a form of logicism proper, it is really not much of a concession to Kantian intuitionists; since the role of the spatial and temporal a priori sources of knowledge was, at first at least, given a very constrained role.

Contrast this line of interpretation with Sluga (1980, p. 173), who writes: "Lotze's logicism has been sacrificed so that Kantian apriorism might live." What is right 
about Sluga's position is that Frege does now give lesser priority to whole numbers (or cardinal numbers generally) than he would have in his earlier work, and greater priority is assigned to the real and complex numbers. This is presumably to be explained by the fact that real and complex numbers have greater applicability in the spatial and temporal realms. Indeed, in the very final manuscripts, Frege considers defining complex numbers using ratios of geometrical lines. The full importance of this change in priority for Frege's way of thinking cannot fully be discerned from the manuscripts.

\section{An Alternative Approach, and Evaluation}

I have so far been focused mainly on sketching the development of Frege's views, and have held back from evaluation. Space constraints shall keep me from doing too much by way of assessment. Luckily, Frege's earlier views, if taken in their entirety, are easy to assess: their impossibility is well-known, and admitted by Frege himself. If a concept is to be understood extensionally as a function from objects to truth-values, and one is thought to exist for every possible mapping; it follows by Cantor's theorem that there must be more concepts than objects. Consequently, it is absurd to maintain that there could be any way of generating a distinct object for every concept. To his credit, Frege did come to realize this; and indeed, in his Appendix on Russell's paradox he shows how there cannot be a second-level function that yields a distinct object for every first-level function as argument.

The more difficult question is the extent to which we might be able to preserve what I tend to think of as the core of Frege's conception of numbers: that numbers either are certain second-level concepts, or are at least highly conceptually and metaphysically related to them in an adequate philosophy of mathematics. I tend to think that this is certainly an attractive beginning for any approach to understanding the nature of numbers, and indeed, the arguments against simply thinking of numbers as second-level concepts that I have seen are not very compelling. At least one such objection - that on this approach, numbers themselves cannot be counted - seems to me to be based on a misunderstanding. Frege's logic countenanced heterogeneous relations, i.e., relations with relata of different types. By means of such relations, a higher-level concept can be said to be equinumerous, or like in cardinality, with a lower-level concept, and its number can be assigned to both. ${ }^{6}$

Nonetheless, as Frege seems to have been aware, however, if numbers are thought of in this way, we need to say more about the nature of our knowledge of

\footnotetext{
${ }^{6}$ See Landini (2006) for further argumentation on this point.
} 
their basic properties. It is implausible, or at least odd, to suppose that we require some empirical proof that the sequence of numbers does not give out at some point. Frege's own final appeal to a geometrical or temporal sources of knowledge are certainly by no means absurd, and deserve further scrutiny. Nevertheless, I'm not at all presently convinced we have any a priori knowledge of the structure of space and time, that it is either infinitely extended or infinitely divisible. For his own part, Frege gives no argument for this conclusion in these manuscripts. Perhaps it is a priori that these are possible structures for space and time, but the metaphysical nature of possibilia is no better established than that of numbers themselves.

Another option that a Fregean might consider - indeed, I find it somewhat surprising that Frege seemingly did not think to pursue this option himself - is to recognize other sorts of abstract objects through which the continuation of the series of numbers can be guaranteed. Consider Frege's own realism about thoughts and other senses, as entities in a third realm distinct from both the mental and physical. It is a matter of controversy whether Frege's theory of senses counts as a logical doctrine, either in his view of what logic is, or in the usual view of what logic is. However, if we do have knowledge of the existence of senses, this knowledge does not seem to derive either from sense perception or from the geometrical and temporal sources of knowledge. If Frege's taxonomy of our sources of knowledge was exhaustive, he himself seems committed to the claim that we are aware of the existence of senses through the logical mode of knowledge. Don't we then have an alternative route for establishing the infinity of objects we need for the purposes of arithmetic? And isn't it perfectly clear that if thoughts exist, an infinite number of them exist? ${ }^{7}$

Yet this suggestion does raise a number of worries. In order to flesh this suggestion out into a full fledged argument for an infinity of objects, much more will need to be said first about how we know that thoughts exist, and also how it is we can count thoughts. In other words we must specify identity conditions for them fine grained enough to give us an infinity. But this has the potential for creating as many problems as it solves. If thoughts are objects, as we require for this strategy to be successful, again by Cantor's theorem, there must be fewer of them than there are concepts. However, if a distinct thought is postulated too readily, we may easily find ourselves committed to at least as many thoughts as concepts: and in all likelihood, this would simply give rise to another paradox. ${ }^{8}$ Indeed, Russell himself tried, apparently without success, to warn Frege of Cantorian paradoxes of this

\footnotetext{
${ }^{7}$ In a posthumously published manuscript, Frege himself expressed sympathy for Dedekind's proof of infinity invoking what can be thought, so long as we acknowledge the existence of thoughts which have not in fact been thought by any thinker - see Frege (1897, p. 136n).

${ }^{8}$ For more on the can of worms that would get opened here, see Klement (2002), especially ch. 7.
} 
variety (see Klement, 2001). So in the end I do have my doubts about a purely logical method for establishing an infinity of objects. For the moment, the fence Frege himself sat on during many of his later years: between thinking that there must be a way of recognizing the existence of objects logically on the one hand, but not quite seeing how to proceed, and abandoning this view in favor of one that does not seem to do justice to the way in which we take ourselves to have arithmetical knowledge, is a fence I'm happy to sit on.

\section{References}

Cocchiarella, Nino (1987). Logical Studies in Early Analytic Philosophy. Columbus: Ohio State University Press.

Frege, Gottlob (1891). "Function and concept.” In Frege (1984), pp. 137-56.

_ (1892a). "Comments on sense and meaning." In Frege (1979), pp. 118-25.

(1892b). “On concept and object.” In Frege (1984), pp. 182-94.

(1892c). "On concept and object [draft]." In Frege (1979), pp. 87-117.

(1895). "A critical elucidation of some points in E. Schröder's Lectures on the Algebra of Logic." In Frege (1984), pp. 211-28.

— (1897). “Logic.” In Frege (1979), pp. 126-151.

(1906). "On Schoenflies: Die logischen Paradoxien der Mengenlehre." In Frege (1979), pp. 176-83.

(1914). "Logic in mathematics." In Frege (1979), pp. 203-250.

(1919). “Notes for Ludwig Darmstädter.” In Frege (1979), pp. 253-57.

(1924a). "Diary entries on the concept of numbers." In Frege (1979), pp. 263-64.

(1924b). "A new attempt at a foundation for arithmetic." In Frege (1979), pp. $278-81$.

(1924c). “Number.” In Frege (1979), pp. 265-66.

(1924d). "Numbers and arithmetic." In Frege (1979), pp. 275-77.

(1924e). "Sources of knowledge of mathematics and natural sciences." In Frege (1979), pp. 267-74.

(1950). The Foundations of Arithmetic. Evanston: Northwestern University Press. Translated by J. L. Austin; first published in 1884 as Die Grundlagen der Arithmetik (Breslau: W. Köbner). 
(1964). Basic Laws of Arithmetic. Berkeley: University of California Press. Translated by M. Furth; originally published in 1893-1902 as Grundgesetze der Arithmetik, 2 vols. (Jena: H. Pohle).

(1979). Posthumous Writings. Chicago: University of Chicago Press. Translated by P. Long and R. White.

(1980). Philosophical and Mathematical Correspondence. Chicago: University of Chicago Press.

(1984). Collected Papers on Mathematics, Logic and Philosophy. New York: Basil Blackwell. Edited by B. McGuinness.

(1997). The Frege Reader. Oxford: Blackwell.

Klement, Kevin C. (2001). "Russell's paradox in appendix B of the Principles of Mathematics: Was Frege's response adequate?" History and Philosophy of Logic 22, 13-28. ledge.

(2002). Frege and the Logic of Sense and Reference. New York: Rout-

(2004). "Putting form before function: Logical grammar in Frege, Russell and Wittgenstein.” Philosopher's Imprint 4, 1-47.

Landini, Gregory (2006). "Frege's cardinal numbers as concept-correlates.” Erkenntnis 65, 207-43.

Quine, W. V. (1955). “On Frege's way out.” Mind 64, 145-59.

Russell, Bertrand (1919). Introduction to Mathematical Philosophy. London: George Allen \& Unwin.

Sluga, Hans (1980). Gottlob Frege. London: Routledge and Kegan Paul. 